\title{
Chemical composition of germinating Tunisian almond (Prunus Amygdalus Mill.) seedlings oil
}

\author{
Refka Dhouibi ${ }^{1}$, Hanen Oueslati ${ }^{2}$, Senda Bahri ${ }^{3}$, Khaled Jabou ${ }^{4}$, Sellema Bahri ${ }^{1{ }^{1}}{ }^{*}$ \\ ${ }^{1}$ Dept. of Biology, Biochemistry Laboratory, Faculty of Sciences Tunis, University of Tunis El \\ Manar, 2092, Tunisia \\ ${ }^{2}$ National medication Control Laboratory, 1006, Tunis, Tunisia \\ ${ }^{3}$ Faculty of Pharmacy, Monastir, Tunisia \\ ${ }^{4}$ National Oil Office, Ezzouhour City, Tunis, Tunisia \\ *Corresponding author: sellemab@gmail.com
}

\begin{abstract}
Almonds (Prunus amygdalus) are a rich source of many essential nutrients. However, there is a lack of enough information on almond varieties' biochemical composition, especially at the germination stage. Therefore, this study was conducted to determine the chemical components of the germinating Tunisian almonds. The study included determining the content of oils, proteins, fatty acids, and triglycerides during germination. Results indicated that the oleaginous seeds are rich in oil (55 to $65 \%$ of the dry mass) and crude protein $(21.825$ $\mathrm{mg} / \mathrm{mL}$ ). The dominant polyunsaturated fatty acids are oleic and linoleic acids which represent $64.53 \%$ and $24.38 \%$, respectively, while palmitic acid is the most dominant saturated fatty acid with $7.65 \%$ of the total fatty acids. Also, the primary molecular types of triglycerides detected by L.C. analysis are triolein $(32.3 \%)$ and dioleolinolein $(24.0 \%)$, followed by palmitodiolein $(12.5 \%)$ and oleodilinolein $(12.6 \%$.). The physico-chemical properties study revealed that almond oil remains stable, thus preserving its quality and nutritional value, even during transition from dormancy to germination. On the other hand, we also detected the presence of a lipolytic activity which is maximum on the $3^{\text {rd }}$ day of germination (4.66 mUI). Our results indicate that almond oil plays an important role in human nutrition due to the presence of unsaturated fatty acids, and it is more stable than other oils.
\end{abstract}

Keywords: Almond oil content; fatty acids; germination; prunus amygdalus; triglyceride.

\section{Introduction}

Almond is an important food crop grown mainly in the Mediterranean region. Almond trees (Prunus amygdalus) have been cultivated in Tunisia for decades, and the plantation was extended mostly in the south of the country, contributing to the economic growth. Tunisia is the seventhlargest producer of almonds in the world and the 5th in the Mediterranean. The annual production of almonds was about 67000 tons, representing 2 to $3 \%$ of this nut's world production (FAOSTAT, 2018).
The cultivar 'Achaak' is the most important in terms of market demand and fruit quality, but unfortunately, it is commonly considered as a low producing genotype (Gouta et al., 2010).

'Achaak' is a tree, vigorous and fertile, especially in its zone of origin (Sfax), with dense foliage of a light green color. However, the time of maturity is hasty; it is between the end of July and early August. The nut is characterized by its rather large seed, long, thin-skinned, smooth, and brown-veined appearance. These physical parameters are very appreciated by consumers (Rabadan et al., 2019). 
Almonds are a rich source of nutrients and phytochemicals such as vitamin E, phytosterols, flavonoid, phenolic compounds, monounsaturated fatty acids, polyunsaturated fatty acids, and proteins (Mandalari et al., 2008; Grundy et al., 2016). In effect, almond lipids, composed predominantly of triacylglycerols (TAGs), are stocked into oil bodies. Usually, depending on the harvest and variety, the kernel is constituted of approximately $50 \%$ of lipids distributed between $70-80 \%$ of oleic acid, 15\% linoleic acid, and 5\% palmitic acid. Furthermore, almond oil contains antioxidants and fat-soluble bioactive compounds that make it oil with interesting nutritional and cosmetic properties (Chung et al., 2013; Ronceroa et al., 2016b). In particular, in the almond kernel, depending on its structure and degree of processing, the amount of lipid released from the almond tissue matrix and the fatty acids produced from lipolysis has been found to vary substantially.

Lipolysis plays a central role in many plants' life cycle by providing the skeletons of carbon and energy that stimulate postgerminative growth. Despite the physiological importance of this process, the molecular mechanism is unknown (Eastmond, 2006). To understand the almond lipolysis mechanism, we tried, as a first approach, to study the total fat content and fatty acid composition of a major glyceride fraction of almond seedlings. We also investigated the presence of a triacylglycerol lipase (EC 3.1.1.3) which catalyzes the breakdown of triacylglycerols to glycerol and free fatty acid.

\section{Methodology}

\subsection{Biological Material}

Germinating Tunisian almonds seeds (Prunus amygdalus Mill.) cultivar 'Achaak,' kindly provided by Olive Institute", Sfax, Tunisia, were collected during crop years 2017-2018. The seeds were germinated during 1 to 6 days at 26 $\pm 1{ }^{\circ} \mathrm{C}$ in the darkness, peeled, dried, and saved till used (Bahri, 2012).

\subsection{Oil Extraction}

Dried seeds were ground in mortar porcelain. According to the ISO method, a known weight (about 5 grams per thimble) of the powdered fat was extracted for 5 hours, with 10 to 15 volumes of petroleum ether in a Soxhlet extractor 659:1998 (ISO, 1999). The solvent was removed with a rotary evaporator under reduced pressure at $50{ }^{\circ} \mathrm{C}$. The extracted oil was kept at $4{ }^{\circ} \mathrm{C}$ for later uses.

Yield of the oil was calculated on dry basis according to Equation 1:

\subsection{Physico-chemical Parameters}

The oil sample color was determined by the technical staff of the National Oil Office of Tunis. The acid value was determined following the established procedure of ISO 660: 2009.

The Iodine Index was determined by the Wijs' method (American Oil Chemists' Society, AOCS Official Method Cd 1-25), and the saponification number was measured by using the ISO Method 3657: 2002.

Properties of almond oil (A.O.) used in the present study were measured following the American Society for Testing and Materials (ASTM) standards.

\subsection{Determination of Fatty Acid}

Fatty acids were converted to their methyl esters (FAME) following the method of methylation with a cold solution of $\mathrm{KOH}$ in methanol (ISO-5509: 2000), and then the esters were analyzed by capillary gas chromatography using high polar columns: $5 \mu \mathrm{L}$ of FAME sample was injected into the gas chromatograph (Model 5890A, Hewlett-Packard, Palo Alto, CA) equipped with a flame ionization detector (FID). G.C. separation was realized on a capillary column HP5 Agilent CP-Sil 88 (50m length, $250 \mu \mathrm{m}, 0.2 \mu \mathrm{m}$ film thickness). The temperatures of the injector and detector were maintained at $280{ }^{\circ} \mathrm{C}$ and $300{ }^{\circ} \mathrm{C}$, respectively. The oven 
temperature was calibrated at $165{ }^{\circ} \mathrm{C}$ for $15 \mathrm{~min}$ followed by an increase of 5 ${ }^{\circ} \mathrm{C} / \mathrm{min}$ to $185^{\circ} \mathrm{C}$, which was maintained for $11 \mathrm{~min}$. The carrier gas was helium at a flow rate of $1.3 \mathrm{~mL} / \mathrm{min}$.

The fatty acids were identified by comparison of their retention times with known standard samples. Finally, fatty acid contents were calculated as percentages.

This program allows separating fatty acids, monoacylglycerols, diacylglycerols, and triacylglycerols.

\subsection{Triacylglycerol Composition}

The TAGs profile of the studied almond seeds oil was determined using highperformance liquid chromatography (HPLC) from Waters Alliance module e2695 equipped with a U.V. detector. The separation of TAGs was made using a commercially packed C18 column $(4.6 \times 150 \mathrm{~mm}$ from Waters). A mixture of acetone/acetonitrile (50:50) using as mobile a phase set at a flow rate of 1.5 $\mathrm{ml} / \mathrm{min}$. A $20 \mu \mathrm{L}$ of the sample prepared with dilution with acetone $5 \%$ was injected into HPLC with a total running time of 60 min.

The identification of TAG peaks was carried out by comparing the TAG chromatograms of olive oil as standards. The data were processed by peak surface normalization and expressed as a percentage of TAG.

\subsection{Measurements of lipase activity}

Lipase (present naturally in plant oils) activity was tested essentially as described by Yesiloglu \& Baskurt, 2008. modified method. Olive oil was used as a substrate. Lipase activity was measured by estimating the release of free fatty acids. One lipase activity unit is defined as the amount releasing one mole of fatty acid in a specific condition. Specific activities are expressed as I.U./mg of protein.

\subsection{Proteins content}

The protein content during germination was carried out according to Bradford, 1976.

\subsection{Statistical analysis}

All tests were performed in triplicate, and all measurements were expressed as mean \pm S.D. ANOVA treated the obtained results of fatty acid content to determine significant differences between means in the statistical program XLSTAT version 2018.4, statistical software for Excel.

\section{Results}

\subsection{Oil content}

'Achaak' total lipid content (Figure 1) varies between 55 and $60 \%$ and gradually decreases during germination.

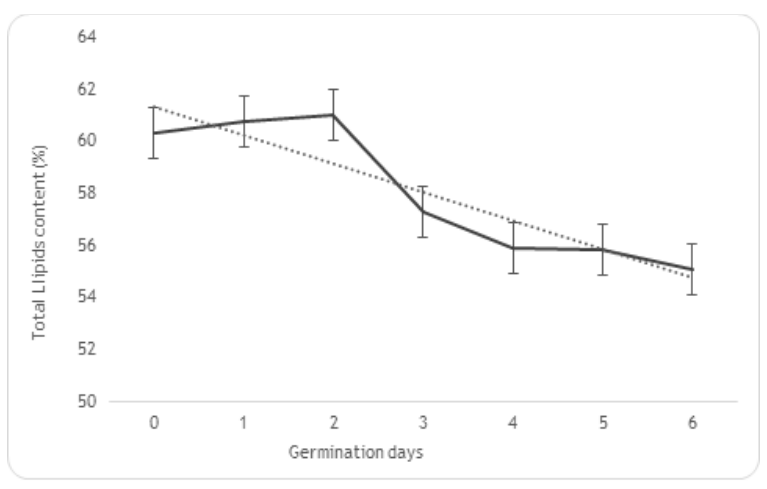

Fig. 1. Total lipids content of almond seeds variety 'Achaak' during germination. A trend line has been added to the figure, which shows decreased lipid content over germination. 
Table 1. Changes in analytic values of almond seeds during germination.

\begin{tabular}{|c|c|c|c|c|c|c|c|}
\hline $\begin{array}{c}\text { Physico-chemical } \\
\text { parameters }\end{array}$ & Imbibition & Day 1 & Day 2 & Day 3 & Day 4 & Day 5 & Day 6 \\
\hline Color & clear & clear & clear & clear & clear & clear & clear \\
\hline Acid value (\%) & $0.3 \pm 0.01$ & $0.35 \pm 0.0$ & $0.4 \pm 0.01$ & $0.5 \pm 0.01$ & $0.6 \pm 0.02$ & $0.6 \pm 0.0$ & $0.6 \pm 0.01$ \\
\hline lodine value & $99.06 \pm 0.05$ & - & - & $96.52 \pm 0.05$ & - & - & - \\
\hline Saponification index & $122.71 \pm 0.39$ & - & - & $129.73 \pm 0.31$ & - & - & - \\
\hline Proteins (mg/mL) & $15.37 \pm 0.08$ & $17.28 \pm 0.01$ & $21.82 \pm 0.16$ & $21.51 \pm 0.12$ & $15.8 \pm 0.12$ & $14.8 \pm 0.18$ & $12.89 \pm 0.09$ \\
\hline
\end{tabular}

$\mathrm{SD} \pm$ : Standard deviation.

\section{2 . Parameters of almond oil physico-} chemical quality

The extracted almond oil has a sweet, light odor, and transparent color. The odor and color of the corresponding oil remain unchanged. Acidity values found on almond oil, increase from 0.3 and 0.6 during germination. The iodine value varied between $99.06 \mathrm{~g} / 100 \mathrm{~g}$ the first three days of germination Vs. $96.52 \mathrm{~g} / 100$ $\mathrm{g}$ of fat the rest of the germinative process (Table 1).

\subsection{Fatty acids composition}

CPG detected thirteen fatty acids in the tested oil samples, including the four major ones (Table 2).

We observed that almond oil's major fatty acid was oleic acid at all days of germination, with $64.74 \%$ on day 2, $64.53 \%$ on day 3 , and $65.76 \%$ on day 4 . Oleic acid was followed by linoleic acid (C18: 2), which represents respectively $24.14 \%, 24.38 \%$, and $23.18 \%$ of days 2,3 , and 4, and palmitic acid (C16: 0$)$, which is $7.38 \%, 7.65 \%$ and $7.38 \%$ on days 2,3 and 4 respectively. 
Table 2. Fatty acid composition of almonds germinating seedlings.

\begin{tabular}{|c|c|c|c|c|c|c|c|}
\hline Fatty acid \% & Imbibition & Day 1 & Day 2 & Day 3 & Day 4 & Day 5 & Day 6 \\
\hline Myristic, C14 & $0.02 \pm 0.0^{\mathrm{e}}$ & $0.02 \pm 0.0^{e}$ & $0.02 \pm 0.0^{e}$ & $0.02 \pm 0.0^{\mathrm{e}}$ & $0.02 \pm 0.0^{e}$ & $0.02 \pm 0.0^{e}$ & $0.02 \pm 0.0^{\mathrm{e}}$ \\
\hline Palmitic, C16:0 & $7.23 \pm 0.45^{c}$ & $7.04 \pm 0.12^{c}$ & $7.38 \pm 0.2^{c}$ & $7.65 \pm 0.24^{c}$ & $7.38 \pm 0.13^{c}$ & $7.17 \pm 0.35^{c}$ & $7.24 \pm 0.04^{c}$ \\
\hline Palmitoleic, C16:1 & $0.44 \pm 0.02^{\mathrm{e}}$ & $0.5 \pm 0.03 \mathrm{e}$ & $0.41 \pm 0.03^{\mathrm{e}}$ & $0.42 \pm 0.02^{\mathrm{e}}$ & $0.45 \pm 0.04^{e}$ & $0.4 \pm 0.03 e$ & $0.51 \pm 0.04^{e}$ \\
\hline Margaric, C17:0 & $0.06 \pm 0.0^{e}$ & $0.05 \pm 0.0^{\mathrm{e}}$ & $0.07 \pm 0.0 \mathrm{e}$ & $0.06 \pm 0.0^{e}$ & $0.06 \pm 0.0^{\mathrm{e}}$ & $0.06 \pm 0.0^{\mathrm{e}}$ & $0.06 \pm 0.0^{e}$ \\
\hline Heptadecanoic, C17:1 & $0.08 \pm 0.0^{e}$ & $0.09 \pm 0.0^{\mathrm{e}}$ & $0.06 \pm 0.0^{e}$ & $0.08 \pm 0.0^{e}$ & $0.08 \pm 0.0^{e}$ & $0.08 \pm 0.0^{e}$ & $0.09 \pm 0.0^{\mathrm{e}}$ \\
\hline Stearic, C18:0 & $2.27 \pm 0.26^{\mathrm{d}}$ & $2.25 \pm 0.4^{d}$ & $2.94 \pm 0.77^{d}$ & $2.94 \pm 0.2^{\mathrm{d}}$ & $2.8 \pm 1.07^{\mathrm{d}}$ & $3.07 \pm 0.58^{d}$ & $2.24 \pm 0.43^{d}$ \\
\hline Oleic (trans), C18:1 & $0.005 \pm 0.0^{\mathrm{e}}$ & $0.008 \pm 0.0^{e}$ & $0.01 \pm 0.0^{\mathrm{e}}$ & $0.01 \pm 0.0^{\mathrm{e}}$ & $0.02 \pm 0.02^{\mathrm{e}}$ & $0.008 \pm 0.0^{\mathrm{e}}$ & $0.009 \pm 0.0 \mathrm{e}$ \\
\hline Oleic (Cis), C18:1 & $66.7 \pm 2.81^{\mathrm{a}}$ & $68.64 \pm 1.96^{\mathrm{a}}$ & $64.74 \pm 2.64^{\mathrm{a}}$ & $64.53 \pm 0.89^{\mathrm{a}}$ & $65.76 \pm 3.02^{\mathrm{a}}$ & $65.63 \pm 1.2^{\mathrm{a}}$ & $67.8 \pm 3.45^{\mathrm{a}}$ \\
\hline Linoleic (trans), C18:2 & $0.02 \pm 0.0^{e}$ & $0.01 \pm 0.0^{e}$ & $0.02 \pm 0.0^{e}$ & $0.02 \pm 0.0^{\mathrm{e}}$ & $0.03 \pm 0.03 \mathrm{e}$ & $0.02 \pm 0.0^{e}$ & $0.02 \pm 0.0^{e}$ \\
\hline Linoleic, C18:2 & $22.98 \pm 2.23^{b}$ & $21.22 \pm 1.73^{\mathrm{b}}$ & $24.14 \pm 2.61^{\mathrm{b}}$ & $24.38 \pm 0.91^{\mathrm{b}}$ & $23.18 \pm 1.88^{b}$ & $23.32 \pm 1.41^{\mathrm{b}}$ & $21.75 \pm 3.07^{\mathrm{b}}$ \\
\hline Arachidic, C20:0 & $0.08 \pm 0.01^{\mathrm{e}}$ & $0.05 \pm 0.01 \mathrm{e}$ & $0.09 \pm 0.01 \mathrm{e}$ & $0.08 \pm 0.0^{\mathrm{e}}$ & $0.08 \pm 0.02^{\mathrm{e}}$ & $0.09 \pm 0.0^{\mathrm{e}}$ & $0.07 \pm 0.0^{\mathrm{e}}$ \\
\hline Linolenic, C18:3 & $0.01 \pm 0.0^{\mathrm{e}}$ & $0.01 \pm 0.0^{\mathrm{e}}$ & $0.01 \pm 0.0^{\mathrm{e}}$ & $0.02 \pm 0.0^{e}$ & $0.02 \pm 0.0^{\mathrm{e}}$ & $0.03 \pm 0.0^{\mathrm{e}}$ & $0.02 \pm 0.0 \mathrm{e}$ \\
\hline Gadoleic, C20:1 & $0.05 \pm 0.0^{\mathrm{e}}$ & $0.05 \pm 0.0^{\mathrm{e}}$ & $0.04 \pm 0.0^{e}$ & $0.04 \pm 0.0^{\mathrm{e}}$ & $0.04 \pm 0.0^{\mathrm{e}}$ & $0.05 \pm 0.0^{e}$ & $0.05 \pm 0.0^{e}$ \\
\hline SFA & 9.66 & 9.41 & 10.5 & 10.75 & 10.34 & 10.41 & 9.63 \\
\hline MUFA & 67.275 & 69.288 & 65.26 & 65.08 & 66.35 & 66.168 & 68.459 \\
\hline PUFA & 23.01 & 21.24 & 24.17 & 24.42 & 23.23 & 23.37 & 21.79 \\
\hline UFA & 90.285 & 90.528 & 89.43 & 89.5 & 89.58 & 89.538 & 90.249 \\
\hline UFA: SFA & 9.34 & 9.62 & 8.51 & 8.32 & 8.66 & 8.6 & 9.37 \\
\hline$O: L$ & 2.9 & 3. 23 & 2.6 & 2. 64 & 2. 83 & 2. 81 & 3. 11 \\
\hline
\end{tabular}

SFA: satured F.A., MUFA: monounsaturated F.A., PUFA: polyunsaturated F.A., UFA: unsaturated F.A., According to

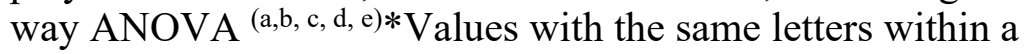
row are statistically similar $(\mathrm{P}<0.05)$. 
Table 3. TAG composition of variety 'Achaak' during germination.

\begin{tabular}{cccccccccc}
\hline TAG & ECN & $\begin{array}{c}\text { Retention } \\
\text { time(min) }\end{array}$ & Imbibition & Day 1 & Day 2 & Day 3 & Day 4 & Day 5 & Day 6 \\
\hline LLL & 42 & 19.8 & $1.8 \pm 0.45$ & $1.7 \pm 0.03$ & $1.7 \pm 0.21$ & $1.9 \pm 0.27$ & $1.7 \pm 0.12$ & $1.8 \pm 0.04$ & $1.6 \pm 0$ \\
OLL & 44 & 25.5 & $12.1 \pm 1.97$ & $11.3 \pm 1.13$ & $11.0 \pm 0.22$ & $12.6 \pm 1.68$ & $12.2 \pm 0.92$ & $12.2 \pm 0.82$ & $10.9 \pm 0.07$ \\
PLL & 44 & 27.3 & $1.9 \pm 0.48$ & $1.6 \pm 0.22$ & $1.8 \pm 0.02$ & $2.1 \pm 0.26$ & $2.0 \pm 0.26$ & $2.1 \pm 0.27$ & $1.7 \pm 0.09$ \\
OOL & 46 & 33.2 & $25.0 \pm 0.24$ & $23.5 \pm 1.57$ & $23.5 \pm 0.24$ & $24.0 \pm 1.2$ & $24.3 \pm 1.2$ & $23.3 \pm 0.78$ & $22.6 \pm 0.39$ \\
PLO & 46 & 35.7 & $9.3 \pm 1.11$ & $8.6 \pm 0.77$ & $9.1 \pm 0.32$ & $10.1 \pm 0.79$ & $9.6 \pm 0.79$ & $9.5 \pm 0.8$ & $8.5 \pm 0.44$ \\
PLP & 46 & 38.2 & $0.4 \pm 0.13$ & $0.4 \pm 0$ & $0.4 \pm 0.15$ & $0.5 \pm 0.16$ & $0.4 \pm 0.16$ & $0.3 \pm 0.13$ & $0.4 \pm 0.23$ \\
OOO & 48 & 44.0 & $33.1 \pm 4.9$ & $34.6 \pm 2.53$ & $34.9 \pm 2.09$ & $32.3 \pm 3.97$ & $32.9 \pm 3.97$ & $31.9 \pm 1.2$ & $37.7 \pm 1.49$ \\
POO & 48 & 47.7 & $12.2 \pm 0.45$ & $12.1 \pm 0.07$ & $12.9 \pm 0.82$ & $12.5 \pm 0.07$ & $12.8 \pm 0.07$ & $13.0 \pm 0.23$ & $12.0 \pm 0.28$ \\
POP & 48 & 51.5 & $0.3 \pm 0.1$ & $0.5 \pm 0$ & $0.3 \pm 0.06$ & $0.3 \pm 0.1$ & $0.3 \pm 0.1$ & $0.3 \pm 0.19$ & $0.4 \pm 0.26$ \\
SOO & 50 & 64.3 & $3.7 \pm 0.5$ & $5.7 \pm 2.63$ & $4.3 \pm 1.28$ & $3.5 \pm 0.03$ & $3.6 \pm 0.03$ & $4.9 \pm 1.08$ & $3.8 \pm 0.26$ \\
POS & 50 & 68.8 & $0.2 \pm 0.05$ & $0.3 \pm 0$ & $0.3 \pm 0.11$ & $0.3 \pm 0.04$ & $0.3 \pm 0.04$ & $0.3 \pm 0.02$ & $0.3 \pm 0.09$ \\
\hline
\end{tabular}

TAG: Triacylglycerol, ECN: Equivalent carbon number. SD \pm Standard deviation

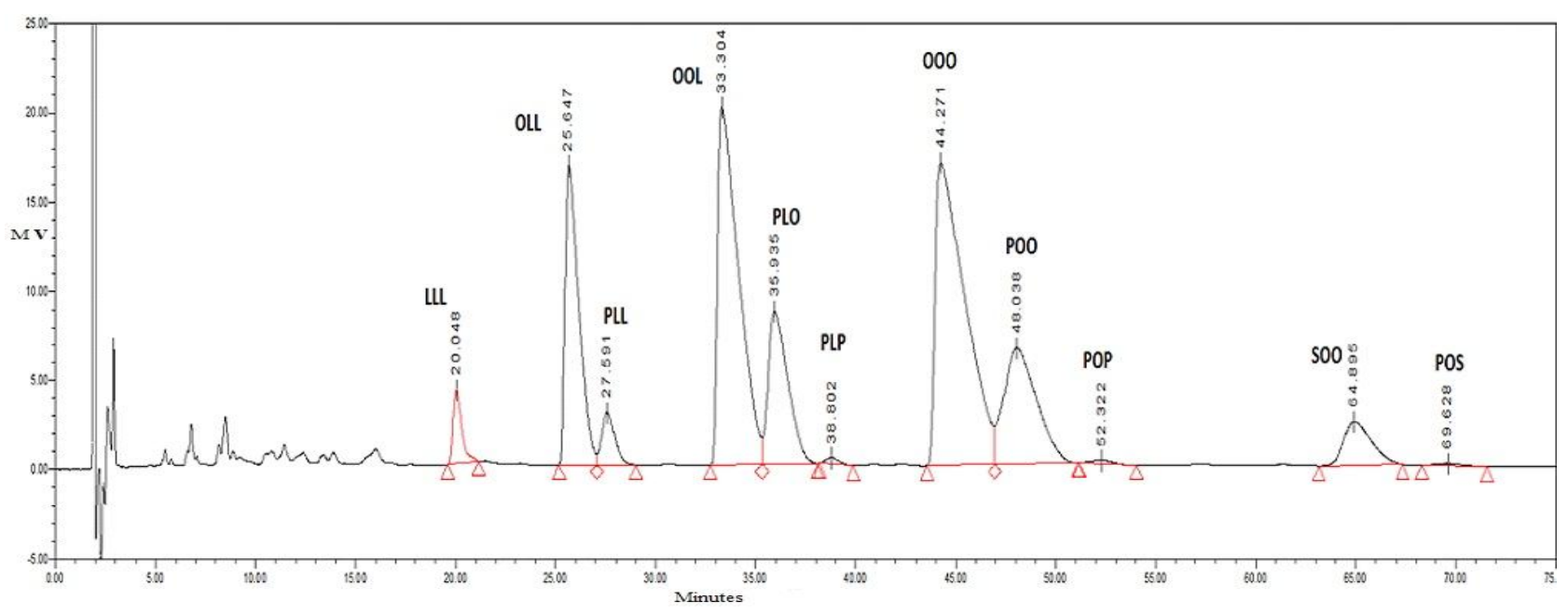

Fig. 2. HPLC analysis of almond seedlings variety 'Achaak' TAG (day 3 of germination) Abreviations: LLL: trilinolein, OOO: triolein, OOL: dioleolinolein, OLL: oleodilinolein,

PLL: palmitodilinolein, PLO: palmitolinoleoolein, PLP: palmitolinoleopalmitin, POO: palmitodiolein, POP: palmitooleopalmitin, POS: palmitooleostearin, SOO: stearodiolein.

\subsection{TAG composition during germination} in almond seeds

HPLC-RP analysis (Table 3) showed the presence of different classes of TAGs in our variety in all germination days.

Thus, two predominant TAG species were observed: triolein (OOO) with $32.3 \%$ and dioleolinolein (OOL) with 24.0\%; followed by three TAGs which are average: palmitodiolein (POO with $12.5 \%$ ), oleodilinolein (OLL) with $12.6 \%$, and palmitolinoleoolein (PLO) with $10.1 \%$. The others are minor (Figure 2) 


\section{5 . Equivalent Carbon Number}

Almond oil was mainly composed of triacylglycerols with an Equivalent Carbon Number (ECN) of 42, 44, 46, 48, and 50. The TAGs of ECN 48 group, such as OOO, OOP, and POP (accounting between $39.71 \%$ and $44.91 \%$ of total TAGs during germination), were higher than those of ECN 46 group (OOL, PLO, and PLP), which accounted for $34.45 \%$ of total TAGs. ECN 40 and ECN 42 groups were minor with respectively $0.4 \%$ and $2.14 \%$ of total TAGs at 4 days of germination (Table 4).

The total percentage of triacylglycerols decreased slightly during germination: from $99.99 \%$ to $98.04 \%$ during 48 hours (from day 2 to day 4). Thus, a decrease rate is obtained during the course of imbibition.

\subsection{Protein content variation}

Our result shows an increase in the total protein content on the first day of germination (Table 1). The protein content was optimal at the 2-day with 21.825 $\mathrm{mg} / \mathrm{mL}$, then gradually decreased to the 6day (to $12.89 \mathrm{mg} / \mathrm{mL}$ ), whereas protein content was higher on days 2 and 3 and lower on day 6 of germination.

\section{7 . Lipolytic activity}

In a previous study, we observed the presence of a true lipase activity during the different days of seed germination of the 'Achaak' variety of almond. The day 3 of germination has the highest enzymatic activity, with a value of $4.66 \mathrm{mU}$ (Figure 3).

Table 4. ECN analysis in Triacylglycerols of variety 'Achaak' during germination.

\begin{tabular}{|c|c|c|c|c|}
\hline TAG (ECN) (\%) & Retention time $(\mathrm{min})$ & Day 2 & Day 3 & Day 4 \\
\hline ECN 40 & 8.04 & $0.35 \pm 0.0$ & $0.45 \pm 0.02$ & $0.4 \pm 0.0$ \\
\hline ECN 42 & 11.69 & $1.92 \pm 0.02$ & $2.36 \pm 0.02$ & $2.14 \pm 0.01$ \\
\hline ECN 44 & 14.6 & $14.72 \pm 0.02$ & $16.4 \pm 0.01$ & $16.41 \pm 0.01$ \\
\hline ECN 46 & 18.53 & $34.45 \pm 0.0$ & $35.88 \pm 0.01$ & $34.45 \pm 0.0$ \\
\hline ECN 48 & 24.00 & $44.91 \pm 0.02$ & $41.08 \pm 0.02$ & $39.71 \pm 0.02$ \\
\hline ECN 50 & 33.73 & $3.62 \pm 0.02$ & $3.79 \pm 0.01$ & $5.28 \pm 0.02$ \\
\hline TAG Total (\%) & - & 99.99 & 99.96 & 98.405 \\
\hline
\end{tabular}

ECN: Equivalent carbon number, S.D. \pm : Standard deviation. 


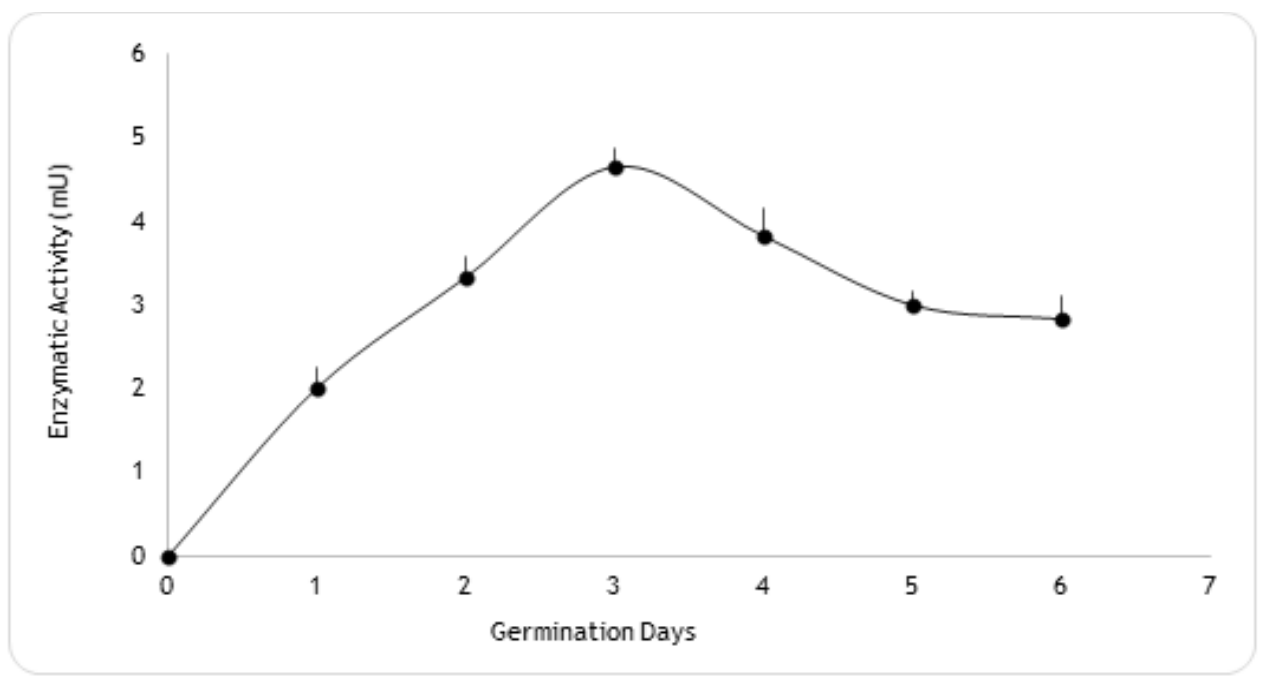

Fig. 3. TAG Lipase activity of almond seeds variety 'Achaak' during germination. The titrimetric lipase activity assay method allowed to highlight certain characteristics of this enzyme such as optimum activity (3-day of germination) at an optimal temperature of $30^{\circ} \mathrm{C}$. Activity is expressed in ' $\mathrm{mU}$ ' ( $\mathrm{nmol} / \mathrm{min})$.

\section{Discussion}

As described by Álvarez-Ortí et al., 2012, and Roncero et al., 2016a, free acidity and iodine index are among the parameters that define the physico-chemical quality of vegetable oils. Almond oil is characterized by very low acidity ( 0.3 to 0.6$)$, which suggests that the samples are fresh and that the oil is of good quality. The free acid content must not exceed $1 \%$ by mass, which indicates that the almond oil is edible. Also, there is a gradual decrease in the iodine index found on almond oil ranged between 96 and 99 during the germination process. These results prove practically almond oil stability.

The auto-hydrolysis of triglycerides plays a role in the hydrolysis of stocked lipids. This is due to environmental conditions such as temperature change, water entry, and consequently the end of dormancy; thus, releasing fatty acids, diacylglycerols (DAGs), and monoacylglycerols (MAGs), and reducing the lipid reserves from day 1 to the final day of germination. This progressive decrease may be due to several factors, such as the action of hydrolytic enzymes (such as esterases) and/ or activity of TAG lipases at the moment of onset of mobilization of lipid reserves. These results are in accordance with those of Cherif et al., 2004, who observed between 50 and $55 \%$ of lipids during the maturation of the cultivar 'Achaak'; Izaddost et al., 2013 , with $48.47 \%$ to $59.16 \%$ of lipids in five different almonds cultivars; Kodad \& Socias, 2008 , with $59.16 \%$ to $48.47 \%$ of lipids for 8 American almonds cultivars, and Sathe et al., 2008 , with $48 \%$ to $67 \%$ of lipids for California-grown almonds.

In effect, diverse studies reported the predominance of oleic, linoleic, palmitic, and stearic acids in almond (Oliveira et al., 2019; Wang et al., 2018; Čolić et al., 2017; Izaddost et al., 2013; Sathe et al., 2008). In other studies, the cultivar 'Achaak' showed a high rate of lipids accumulation compared to two other cultivars ('Mazetto' and 'Beaded'), and the proportion of oleic acid dominated at a later day of maturation for three almond cultivars (Cherif et al., 2004). Chung et al., 2013, also found that oleic acid in almonds was $67.1 \%$ in maturing, which was the highest among the 
other nuts and seeds, while it was $60.9 \%$ in walnut cashew and macadamia nuts. In Taiyuan almond oil, oleic acid was about $68 \%$, with $25 \%$ of linoleic acid, $4.6-4.8 \%$ of palmitic acid, and a little of palmitoleic acid, stearic acid, and arachidic acid. The oleic acid content decreased during germination until day $3(68.64 \%$ to $64.53 \%$ ) and then gradually increased, inversely to the linoleic acid content, which increased $(21.22 \%$ to $24.38 \%)$. As a result, at the same germination days, the ECN 48 group contents decreased from $44.91 \%$ (day 2) to $39.71 \%$ (day 4), and the TAGs slightly decreased from 99.99 to 98.4\%. Linolenic and myristic acids were found at very low concentrations $(<0.1 \%)$.

In fact, the oleic/linoleic acid ratio $(\mathrm{O} / \mathrm{L}$ ratio) is used to determine the nutritional quality of kernel (kodad et al., 2013) as well as its preventive effect on lipid oxidation (Zacheo et al., 2000). This ratio depends primarily on genotype but is also influenced by some conditions (Čolić et al., 2018). Indeed, the germinating almond seeds store more oleic acid than linoleic acid. The amount of linoleic acid provided makes it possible to affirm that the seed furnishes this essential fatty acid, the precursor of the polyunsaturated fatty acids of the n- 6 series. This gives the almond seed lipids an interesting nutritional value.

During germination, the fatty acid composition varies, and unsaturated fatty acids are the major compounds. Thus, almond seeds contain a higher percentage of mainly monounsaturated fatty acids 'MUFA', which varies between 65.08\% and $69.2 \%$, than polyunsaturated fatty acids 'PUFA' $(21.2 \%$ and $24.4 \%)$, and make up about $90 \%$ of the total F.A. during the germination process. MUFA has been reported to be as effective in reducing the cholesterol level in human beings as PUFA (Kodad \& Socias, 2008; Kurbaşlar et al., 2012). Considering the average of germination days, the mean UFA/SFA ratio was about $9 \%$ (Table 2) which decreased till day 3 and then increased till the end. Our results confirmed the predominance of triolein and dioleolinolein, as reported by Cherif et al., 2004, who proved and indicated that the TAG content of Prunus amygdalus could vary from one variety to another. According to Gigliotti et al., 1988, some almond cultivars' TAG composition may be comparable to that of olive oil as a standard.

During maturation, oil seeds synthesize significant amounts of TAGs in lipid subcellular droplets called LDs (Huang, 2018). These stored TAGs are rapidly mobilized for seedling post-germinative growth. The first step of TAGs hydrolysis is catalyzed by a TAG lipase. Beisson et al., 2001, have shown that in vitro plant lipases have a certain efficiency in almonds oil bodies lipolysis, for which the enzyme did not require any protein cofactor. Also, the TAGs of oil bodies can also be hydrolyzed by the lipolytic enzyme without pre-hydrolysis of the oleosin layer.

This well-known TAG lipase role could explain the significant decrease of oil content after $48 \mathrm{~h}$ from $60.77 \%$ to $55.05 \%$. This decrease in total lipids levels was observed during the germination from day 2 to day 6. In Effect, the TAG levels on day 1 after imbibition were similar to those of ungerminated dry seeds. They began to decrease steadily from day 2 to day 6 . We have also observed the decrease in ECN 48 group contents from day $2(44.91 \%)$ to day $4(39.71 \%)$, which suggests the catalysis of triolein by lipases. Figure 3 indicates the progressive enhancement of the lipasic activity, from imbibition to day 3 with an optimum of $4.66 \mathrm{mU}$ at day 3 , then a decrease of the activity to day 6 of germination. The period from day 4 to day 6 could correspond to the progressive inactivation of the enzyme. In fact, it has been reported that lipase activity is absent in ungerminated seeds and increases rapidly when germination starts (Villeneuve, 2003; Barros et al., 2010).

The levels of the detected lipase can account for the degradation of TAGs. The 
free fatty acid contents of the seeds increased till 24 hours but decreased after that. This may be due to the increase of the hydrolysis of TAGs and then the conversion of free fatty acids to sucrose and their mobilization to the growing embryonic axis.

Concerning the protein content variation, Bewley, 1997, has shown the presence of stored proteins in the seeds. This would explain the zero-day protein content of $15.37 \mathrm{mg} / \mathrm{mL}$. The increase in protein content would be related to the triggering of lipolysis and the neosynthesis of new proteins appearing at specific times, including the lipase(s) involved in the degradation and metabolism of TAGs during germination (Müntz et al., 2001). It could also correspond to structural proteins of the growing seedling (Bewley et al., 2013).

Bahri, 2012, has observed the presence of a lipolytic activity in germinating almonds seeds in diverse recovered fractions during their purification. However, this activity remains very weak in vitro, and all kinetic studies and lag analyses suggested that the oleosin/ phospholipid coat of almond seeds oil bodies slow down hydrolysis by lowering the specific activity of TAG Lipase and by inducing a lag time to occur (Beisson et al., 2001). Consequently, this low TAG Lipase activity may explain the non-drastic variation of F.A. and TAG levels in our study during germination.

\section{Conclusions}

This study revealed that oleic and linoleic acids were, respectively, the main MUFA and PUFA in almond oil (cultivar 'Achaak'). During germination, the oleic acid content ranges between $64.53 \%$ and $68.64 \%$ of the total fatty acids. Regarding TAG, the most important ones were OOO, OOL, POO, and OLL. We observed a decrease in protein content (21.82 to 12.89 $\mathrm{mg} / \mathrm{ml})$. Some of the physico-chemical parameters of almond oil have been studied, showing an increase in the acid value, the saponification value, and the iodine index during germination. These results are important for nutritional science because fatty acids, triglycerides, and fatsoluble compounds seem to have a major health impact.

Studying changes in the total fat content, protein contents, FAs and TAGs, and enzymatic activities of TAG lipase of almond during germination can also provide important insights into TAG metabolism mechanisms, specifically in almond trees.

\section{ACKNOWLEDGEMENTS}

The authors are grateful to the Oil Office of Sousse, Tunisia (to Mr. Mohamed Daassa and Mr. Haithem Ben Romdhane) for helping in the chromatographic analysis.

\section{References}

Álvarez-Ortí, M.; Quintanilla, C.; Sena, E.; Al-varruiz, A. \& Pardo, J. (2012) The effects of a pressure extraction system on the quality parameters of different virgin pistachio (Pistacia vera L. var. 'Larnaka') oils. Grasas y Aceites, 63(3): 260-266.

Bahri, S. (2012) Lipolytic activity and chilling requirement for germination of some almond cultivars. African Journal of Biotechnology, 11: 14096-14101.

Barros, M.; Fleuri, L.F.\& Macedo, G.A. (2010) Seed lipases: Sources, applications, and properties. Brazilian Journal of Chemical Engineering, 27(01): 15-29.

Beisson, F.; Ferté, N.; Bruley, S.; Voultoury, R.; Verger, R. et al. (2001) Oil-bodies as substrates for lipolytic enzymes. Biochimica et Biophysica Acta- Molecular and Cell Biology of Lipids, 1531(1-2): 47-58.

Bewley, J.D. (1997) Seed germination and dormancy. Plant Cell, 9: 1055-1066. 
Bewley, J.D.; Bradford, K.J.; Hilhorst, H.W.M. \& Nonogaki, H. (2013) Seeds: Physiology of Development, Germination, and Dormancy. (3rd Ed.). Springer-New York. Pp. 392.

Bradford, M.M. (1976) A rapid and sensitive method for the quantitation of microgram quantities of protein utilizing the principle of protein-dye binding. Analytical Biochemistry, 72: 248-254.

Cherif, A.; Sebei, K.; Boukhchina, S.; Kallel, H.; Belkacemi, K. et al. (2004) Kernel fatty acid and triacylglycerol composition for three almond cultivars during maturation. Journal of the American Oil Chemists' Society, 81: 901905.

Chung, K.H.; Shin, K.O.; Hwang, H.J. \& Choi, K.S. (2013) Chemical composition of nuts and seeds sold in Korea. Nutrition Research and Practice, 7: 82-88.

Čolić, S.; Akšić, M.; Lazarević, K.; Zec, G.; Gašić, U. et al. (2017) Fatty acid and phenolic profiles of almond grown in Serbia. Food Chemistry, 234: 455-463.

Čolić, S.; Zec, G.; Bakić, I.; Janković, Z.; Rahović, D., et al. (2018) Rootstock effect on some quality characteristics of almond cultivars 'Troito', 'Marcona' and 'Texas'. Acta Horticulturae, 1219: 19-23.

Eastmond, P.J. (2006) SUGARDEPENDENT1 Encodes a Patatin Domain Triacylglycerol Lipase That Initiates Storage Oil Breakdown in Germinating Arabidopsis Seeds. Plant Cell, 18: 665675.

\section{FAOSTAT(2018)}

http://www.fao.org/faostat/en/\#data/QC.

Gigliotti, C.; Daghetta, A.A. \& Sidoli, A. (1988) Investigation into the composition of triglycerides in virgin olive oils of various origins. Rivista Italiana Delle Sostanze Grasse, 70: 483-489.

Gouta, H.; Ksia, E.; Buhner, T.; Moreno, M.Á.; Zarrouk, M. et al. (2010) Assessment of genetic diversity and relatedness among Tunisian almond germplasm using SSR markers. Hereditas, 147: 283-292.

Grundy, M.M.L.; Lapsley, K. \& Ellis, P.R. (2016) A review of the impact of processing on nutrient bioaccessibility and digestion of almonds. Institute of Food Science and Technology, 51: 1937-1946.

Huang, A.H.C. (2018) Plant lipid droplets and their associated proteins: Potential for rapid advances. Plant Physiology, 176(3): 1894-1918.

ISO (1999) Oilseeds-Determination of hexane extract (or light petroleum extract), called "oil content" ISO, Geneva, Switzerland.

ISO (2000) Method of analysis. Preparation of the fatty acid methyl esters from olive oil and olive-pomace oil.

ISO (2009) Animal and vegetable fats and oils-Determination of acid value and acidity.

Izaddost, M.; Imani, A.; Piri, S. \& Bagiri, A.M. (2013) Oil Content, Major Fatty Acids Composition, $\alpha$ tocopherol, $\beta$ tocopherol and Nut Characteristics of Almond at Time of Harvest. Journal of Basic and Applied Scientific Research, 3: 201-205.

Kırbaşlar, F.G.; Turker, G.; OzsoyGunes, Z.; Unal, M.; Dulger, B. et al. (2012) Antioxidant and antimicrobial Activity, Mineral Composition and Calorie Values of some Nuts and Seeds from Turkey. Records of Natural Products, 6(4): 339.

Kodad, O. \& Socias I Company, R. (2008) Variability of oil content and of 
major fatty acid composition in Almond (Prunus amygdalus Batsch) and its relationship with kernel quality. Journal of Agricultural and Food Chemistry, 56(11): 4096-4101.

Kodad, O.; Estopan, G.; Juan, T. \& Socias I Company, R. (2013) Protein content and oil composition of almonds from Moroccan seedlings: Genetic diversity, oil quality, and geographical origin. Journal of the American Oil Chemists' Society, 90(2): 243-252.

Mandalari, G.; Nueno-Palop, C.; Bisignano, G.; Wickham, M.S.J. \& Narbad, A. (2008) Potential prebiotic properties of almonds (Amygdalus communis L.). Seeds, 74: 4264-4270.

Mntz, K.; Belozersky, M.A.; Dunaevsky, Y.E.; Schlereth, A. \& Tiedemann, J. (2001) Stored proteinases and the initiation of storage protein mobilization in seeds during germination and seedling growth. Journal of Experimental Botany, 52: 1741-1752.

Oliveira, I.; Meyer, A.S.; Afonso, S.; Aires, A.; Goufo, P. et al. (2019) Phenolic and fatty acid profiles, atocopherol and sucrose contents, and antioxidant capacities of understudied Portuguese almond cultivars. Journal of Food Biochemistry, 43: 12887.

Rabadan, A.; Alvarez-Orti, M.; Pardo, J.E. (2019) Morphological, mechanical and sensory properties of almond (Prunus dulcis L.) and pistachio (Pistacia vera L.) cultivars grown in Spain. Kuwait Journal of Sciences, 46(3): 103-113.

Roncero, J.M.; Álvarez-Ortí; M., PardoGiménez, A.; Gómeza, R.; Rabadán, A. \& Pardo, J.E. (2016a) Almond virgin oil: parameters of regulated physicochemical quality and stability. Rivista Italiana Delle Sostanze Grasse, 93: 237-243.
Roncero, J.M.; Álvarez-Ortí, M.; PardoGiménez, A.; Gmeza, R.; Rabadn, A. \& Pardo, J.E. (2016b) Virgin almond oil: Extraction methods and composition. Grasas Aceites, 67: 143.

Sathe, S.K.; Seeram, N.P.; Kshirsagar, H.H.; Heber, D. \& Lapsley, Ka. (2008) Fatty acid composition of Californiagrown almonds. Journal of Food Science, 73: 607-614.

Villeneuve, P. (2003) Plant lipases and their applications in oils and fats modification. European Journal of Lipid Science and Technology, 105: 308-317.

Wang, W.; Wang, H.L.; Xiao, X.Z. \& Xu, X.Q. (2018) Wild almond (Amygdalus pedunculata Pall.) as a potential nutritional resource for the future: studies on its chemical composition and nutritional value. Journal of Food Measurement and Characterization, 13(1): 250-258.

Yesiloglu, Y. \& Baskurt, L. (2008) Partial purification and characterization of Almond seed lipase. Preparative Biochemistry \& Biotechnology, 38: 397-410.

Zacheo, G.; Cappello, M.S.; Gallo, A.; Santino, A. \& Cappello, A.R. (2000) Changes associated with postharvest aging in almond seeds. Lebensm wiss technology, 33: 415-423.

Submitted : :06/04/2020

Revised : 29/06/2020

Accepted : :29/06/2020

DOI $\quad: 10.48129 /$ kjs.v48i2.9308 